\title{
An Experimental Study on Mitigating Alkali Silica Reaction by Using Fly Ash (FA) in Combination with Silica Fume and Expanded Perlite Powder (EPP)
}

\author{
Mohd Isneini $^{1, a}$, Yasutaka Sagawa ${ }^{1}$, Hidenori Hamada ${ }^{1}$ and Daisuke Yamamoto ${ }^{1}$ \\ ${ }^{1}$ Faculty of Engineering, Kyushu University, Nishi-ku, Fukuoka 819-0395, Japan
}

\begin{abstract}
ASR suppression by FA, SF, EPP, FA in combination with SF and EPP were evaluated by both mortar bar and concrete prism test. Mortar bars were made based on JIS A 1146, meanwhile concrete prism bars were casted in accordance with Rilem AAR-3. Both specimens were stored in $40^{\circ} \mathrm{C} 100 \%$ R.H. controlled room. Mortar and concrete mixtures used reactive aggregate in pessimum proportion. The results indicated that FA in combination with $\mathrm{SF}$ and EPP showed smaller expansion compared to FA. The best of concrete mixtures in reducing expansion is combination of FA with SF (FA15SF10).
\end{abstract}

\section{Introduction}

Fly ash (FA) is a by-product of the combustion of pulverized coal in electric power plants. Silica fume $(\mathrm{SF})$ is a by-product of the smelting process in the silicon and ferrosilicon industry that is used as a pozzolan. SF also referred to as micro silica or condensed silica. SF shows pozzolanic reaction and micro filler effect, and they lead to improve durability of concrete. Moreover, perlite is also a pozzolan due to its glassy structure and high $\mathrm{SiO}_{2}$ and $\mathrm{Al}_{2} \mathrm{O}_{3}$ contents. There are studies on the utilization of minerals to inhibit alkali silica reaction (ASR), such as; it is widely accepted that the use of FA at the level of $15 \%$ to $25 \%$ are considered to be sufficient in mitigating concrete expansion. Tanaka et al. [1] concluded that the significant amount of both alkali and hydroxide ions were consumed by additives in ion analysis of pore fluid [1]. Shehata et al. showed that pastes containing SF increased alkalinity at ages beyond 28 days, while pastes containing ternary blends maintained the low alkalinity of the pore solution throughout 3 years testing period [2].

The objective of this study was intended to determine the performance of mineral combination; FA with SF and FA with expanded perlite powder (EPP). Minerals were combined at $15 \%$ and $25 \%$ of FA. In this study, mortar bars were made based on JIS A 1146 , and mortars were treated under $40^{\circ} \mathrm{C}$, and R.H. $100 \%$ of controlled room for expansion measurement. Meanwhile, concrete prisms were made according to RILEM AAR-3, and specimens were also cured in a controlled room under $40^{\circ} \mathrm{C}$, and R.H. $100 \%$ for expansion test. Then, for compressive strength test, the specimens were cured in a controlled room under $20^{\circ} \mathrm{C}$, and R.H. $60 \%$.

\footnotetext{
${ }^{a}$ Corresponding author : isneini-m@doc.kyushu-u.ac.jp
} 


\section{Material and Mixture Proportions}

\subsection{Materials}

Four types of binder were used in this study, namely; Ordinary Portland Cement (OPC), FA, SF and EPP. Chemical composition of OPC, FA, SF and EPP are shown in Table 1. It can be seen in Table 1 that there is no content of $\mathrm{Na}_{2} \mathrm{O}$ and $\mathrm{K}_{2} \mathrm{O}$ in SF. However, the content of $\mathrm{Na}_{2} \mathrm{O}$ and $\mathrm{K}_{2} \mathrm{O}$ in EPP and FA are higher than OPC. OPC, FA, and SF meets the requirements of JIS R 5202, JIS A6201, and JIS A 6207, respectively.

Table 1. Chemical compositions of OPC, FA, SF and EPP.

\begin{tabular}{|c|c|c|c|c|}
\hline Constituents (\%) & OPC & FA & SF & EPP \\
\hline $\mathrm{SiO}_{2}$ & 20.89 & 54.96 & 95.5 & 65.85 \\
\hline $\mathrm{SO}_{3}$ & 2.02 & 0.49 & 0.18 & - \\
\hline $\mathrm{MgO}$ & 0.92 & 1.30 & 0.56 & 0.14 \\
\hline $\mathrm{Na}_{2} \mathrm{O}$ & 0.35 & 1.07 & - & 4.68 \\
\hline $\mathrm{K}_{2} \mathrm{O}$ & 0.36 & 1.30 & - & 4.07 \\
\hline $\mathrm{LoI}$ & 1.87 & 2.37 & 1.22 & - \\
\hline
\end{tabular}

Physical properties of materials are presented in Table 2. Two aggregates were used in this experiment; one was classified as alkali silica reactive (andesite) and the other was classified as nonreactive (limestone).

Table 2. Physical properties of materials.

\begin{tabular}{|c|c|}
\hline Material & Properties \\
\hline Cement (OPC) & Density $=3.16 \mathrm{~g} / \mathrm{cm}^{3}$, Specific Surface Area $=3330 \mathrm{~cm}^{2} / \mathrm{g}$ \\
\hline FA (type II) & Density $=2.26 \mathrm{~g} / \mathrm{cm}^{3}$, Specific Surface Area $=3972 \mathrm{~cm}^{2} / \mathrm{g}$ \\
\hline SF & Density $=2.35 \mathrm{~g} / \mathrm{cm}^{3}$, Specific Surface Area $=18 \mathrm{~m}^{2} / \mathrm{g}$ \\
\hline EPP & Pass sieve No. $200(0.075 \mathrm{~mm})$, Density $=2.58 \mathrm{~g} / \mathrm{cm}^{3}$ \\
\hline Sand (Limestone) & $\begin{array}{l}\text { Density }(\mathrm{SSD})=2.70 \mathrm{~g} / \mathrm{cm}^{3}, \text { Water absorption }=0.61 \%, \mathrm{Rc} \\
=8 \mathrm{mmol} / 1 . \mathrm{Sc}=1 \mathrm{mmol} / 1 .\end{array}$ \\
\hline $\begin{array}{l}\text { Gravel (1): } \\
\text { (Andesite) }\end{array}$ & $\begin{array}{l}\text { Density }(\mathrm{SSD})=2.60 \mathrm{~g} / \mathrm{cm}^{3}, \text { Water absorption }=2.75 \%, \mathrm{Rc} \\
=185 \mathrm{mmol} / 1 . \mathrm{Sc}=620 \mathrm{mmol} / 1 .\end{array}$ \\
\hline $\begin{array}{l}\text { Gravel (2): } \\
\text { (Limestone) }\end{array}$ & $\begin{array}{l}\text { Density }(\mathrm{SSD})=2.70 \mathrm{~g} / \mathrm{cm}^{3}, \text { Water absorption }=0.55 \%, \mathrm{Rc}= \\
8 \mathrm{mmol} / \mathrm{l} . \mathrm{Sc}=1 \mathrm{mmol} / \mathrm{l} .\end{array}$ \\
\hline
\end{tabular}

\subsection{Mixture proportions}

This study presents an experimental study on mortar and concrete mixtures. Mortar and concrete mixtures were prepared based on the same level of mineral percentage. Mortar bars were casted based on JIS A 1146. Andesite coarse aggregates were crushed to become fine aggregates that meets the requirement of particle size distribution in JIS A 1146. Water to cement ratio for mortar was adjusted to 0.50 and alkali content was set to $\mathrm{Na}_{2} \mathrm{O}_{\text {eq }}$ of 1.2 weight \% cement by adding $\mathrm{NaOH}$ solution into mixing water. In addition, concrete prisms were made based on RILEM AAR-3. Concrete mixtures were prepared by using tap water with water binder ratio 0.5. Mixture 1 was made for control, Mixture 2 and 3 used FA at 15\%, and 25\%. Mixture 4, 5 and 6 used SF at 5\%, 10\%, and 15\%; Mixture 7, 8 and 9 used EPP at 10\%, 15\%, and 20\%. Furthermore, mixture 10 and mixture 11 used combination of FA and SF. Mixture 10 used FA10\%, and SF5\%, then mixture 11 used FA15\% and SF10\%. Mixture 12, and mixture 13 were made for combination FA and EPP. Mixture 12 used FA10\% and EPP5\%, then mixture 13 used FA15\%, and EPP10\%. Moreover, test results were evaluated to investigate the effectiveness of FA, SF, EPP, and combination of them in mitigating 
ASR. Total alkali in concrete were determined around $6 \mathrm{~kg} / \mathrm{m}^{3}$. Mix 1 up to Mix 6 , total alkali are 6 $\mathrm{kg} / \mathrm{m}^{3}$. Then, Mix 7 to Mix 13 are: $6.4 \mathrm{~kg} / \mathrm{m}^{3}, 6.6 \mathrm{~kg} / \mathrm{m}^{3}, 6.8 \mathrm{~kg} / \mathrm{m}^{3}, 6.0 \mathrm{~kg} / \mathrm{m}^{3}, 6.0 \mathrm{~kg} / \mathrm{m}^{3}, 6.1 \mathrm{~kg} / \mathrm{m}^{3}$, $6.4 \mathrm{~kg} / \mathrm{m}^{3}$, successively. Mixture proportions of concrete are shown in Table 3 .

Table 3(a). Mixture proportions of concrete.

\begin{tabular}{|c|c|c|c|c|c|c|c|c|c|c|c|c|}
\hline \multirow[b]{2}{*}{ Mix } & \multirow{2}{*}{$\begin{array}{l}\text { w/b } \\
(\%)\end{array}$} & \multirow{2}{*}{$\begin{array}{c}\text { s/a } \\
(\%)\end{array}$} & \multicolumn{8}{|c|}{$\left(\mathrm{kg} / \mathrm{m}^{3}\right)$} & \multicolumn{2}{|c|}{$\left(g / m^{3}\right)$} \\
\hline & & & Water & OPC & FA & SF & EPP & Sand & Gravel & $\mathrm{NaOH}$ & $\mathbf{W R}+\mathbf{A E}$ & $\mathbf{A E}$ \\
\hline 1 & 50 & 45 & 160 & 320 & & - & - & 843 & 992 & 1.856 & 1000 & 12.8 \\
\hline 2 & 50 & 45 & 160 & 272 & 48 & - & - & 836 & 984 & 2.499 & 1000 & 9.60 \\
\hline 3 & 50 & 45 & 160 & 240 & 80 & - & - & 831 & 978 & 2.928 & 1000 & 16.0 \\
\hline 4 & 50 & 45 & 160 & 304 & - & 16 & - & 841 & 990 & 2.070 & 1000 & 12.8 \\
\hline 5 & 50 & 45 & 160 & 288 & - & 32 & - & 838 & 987 & 2.285 & 1000 & 12.8 \\
\hline 6 & 50 & 45 & 160 & 272 & - & 48 & - & 836 & 984 & 2.499 & 1760 & 22.0 \\
\hline 7 & 50 & 45 & 160 & 288 & - & - & 32 & 838 & 987 & 3.613 & 1400 & 17.6 \\
\hline 8 & 50 & 45 & 160 & 272 & - & - & 48 & 836 & 984 & 4.491 & 1400 & 17.6 \\
\hline 9 & 50 & 45 & 160 & 256 & - & - & 64 & 833 & 981 & 5.370 & 1400 & 17.6 \\
\hline 10 & 50 & 45 & 160 & 272 & 32 & 16 & - & 824 & 970 & 5.706 & 880 & 12.8 \\
\hline 11 & 50 & 45 & 160 & 240 & 48 & 32 & - & 813 & 957 & 5.946 & 880 & 12.8 \\
\hline 12 & 50 & 45 & 160 & 272 & 32 & - & 16 & 824 & 970 & 3.163 & 880 & 12.8 \\
\hline 13 & 50 & 45 & 160 & 240 & 48 & - & 32 & 813 & 957 & 4.256 & 880 & 12.8 \\
\hline
\end{tabular}

$(\mathrm{WR}+\mathrm{AE})=$ water reducing and air entraining agent, $\mathrm{AE}=$ air entraining agent

Table 3(b). Mixture proportions of concrete.

\begin{tabular}{|c|c|c|c|c|c|c|}
\hline Mix & w/b (\%) & s/a (\%) & Temp ( $\mathbf{0} \mathbf{C})$ & Slump (mm) & $\begin{array}{c}\text { Air } \\
\text { Content (\%) }\end{array}$ & $\begin{array}{c}\text { Compressive } \\
\text { Strength (MPa) }\end{array}$ \\
\hline 1 & 50 & 45 & 19 & 80 & 5.0 & 32.52 \\
\hline 2 & 50 & 45 & 23 & 150 & 4.0 & 30.05 \\
\hline 3 & 50 & 45 & 22 & 180 & 2.8 & 30.55 \\
\hline 4 & 50 & 45 & 22 & 70 & 3.8 & 33.77 \\
\hline 5 & 50 & 45 & 21 & 60 & 3.5 & 43.86 \\
\hline 6 & 50 & 45 & 30 & 30 & 5.0 & 48.30 \\
\hline 7 & 50 & 45 & 24 & 57 & 4.0 & 27.26 \\
\hline 8 & 50 & 45 & 25 & 65 & 2.9 & 31.62 \\
\hline 9 & 50 & 45 & 22 & 55 & 3.9 & 35.89 \\
\hline 10 & 50 & 45 & 21 & 125 & 4.5 & 35.49 \\
\hline 11 & 50 & 45 & 21 & 125 & 3.1 & 37.65 \\
\hline 12 & 50 & 45 & 20 & 100 & 3.3 & 31.75 \\
\hline 13 & 50 & 45 & 20 & 90 & 2.9 & 32.69 \\
\hline
\end{tabular}

\section{Expansion Test}

\subsection{Mortar bar test}

The size of the mortar was $40 \times 40 \times 160 \mathrm{~mm}$. Samples were wrapped with wet paper and placed vertically in stainless container, then stored in a $40^{\circ} \mathrm{C}$, and $100 \%$ R.H. of controlled room. Measurement was conducted to observe expansion behavior of mortar at day 1, 2 weeks, 4 weeks, 8 weeks, 12 weeks and 24 weeks. 


\subsection{Concrete prism test}

The size of the prism was $75 \times 75 \times 250 \mathrm{~mm}$. Prisms were wrapped with wet paper and thin plastic sheet. Then, specimens were placed vertically in a polyethylene container with constant level of water at the bottom. Moisture control was important for concrete prisms. A piece of wet unwoven paper (size: 355 x $425 \mathrm{~mm}$ ) was used to wrap a specimen. Then, prism was covered with thin plastic sheet. Then, polyethylene containers were stored in a $40^{\circ} \mathrm{C}$ and $100 \%$ R.H. of controlled room. Before measuring, the container was taken to $20^{\circ} \mathrm{C}$ room to cool the specimens for 24 hours. After completing the measurement, the specimens were taken in controlled room. The length of concrete was measured periodically every two weeks. The observation for concrete expansion was conducted in 365 days.

\subsection{Compressive strength test}

Concrete cylinders were demoulded after 24 hours of casting. Compressive test was conducted after 28 days of curing in accordance with JIS A 1108. The average values of compressive were determined from three specimens for each concrete mixture.

\section{Results and Discussion}

\subsection{Mortar bar}

Mortar expansion at the age of 6 months with various aggregate combination ratios is shown in Figure 1. The expansion reached maximum level when the ratio was 30:70 between reactive and non-reactive aggregate. Figure 2 showed that without minerals, expansion increased slowly until eight weeks, then remarkably increased until the end of the observation. It can be seen that expansion was reduced due to usage of FA, SF and EPP. The mortar expansion with FA at level $25 \%$ was lower than mortar expansion with FA at level 15\%. The mortar expansion with SF at level 5\% was lower than mortar expansion without SF. Furthermore, mortar expansion with SF at level 10\% was lower than mortar with SF5\%. Then, the usage of SF15\% showed the lowest expansion. The expansion reduction by SF $10 \%$, and SF $15 \%$ were under $0.1 \%$, that classified as innocuous. Mortar expansion with EPP $10 \%$ increased remarkably. However, became lower than control at the end of test period. Mortar expansion with EPP15\% increased gradually but became lower than EPP10\%. Mortar with 20\% of EPP showed the lowest expansion. Moreover, expansion reduction by using FA in combination with SF and EPP were under $0.1 \%$, that classified as innocuous.

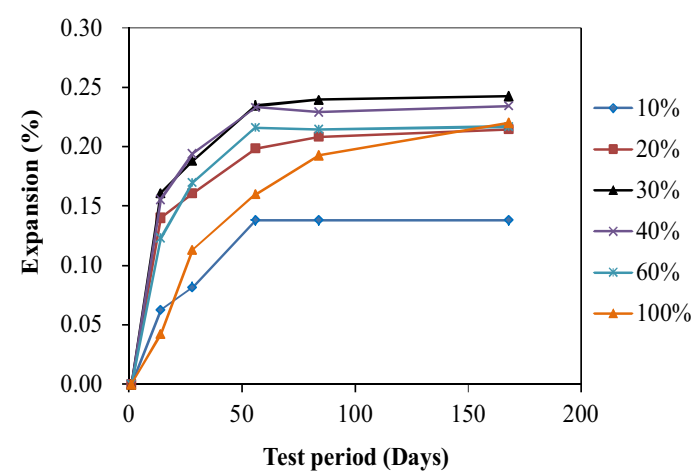

Figure 1. Expansion of mortar at the age of 6 months reactive aggregate ratio.

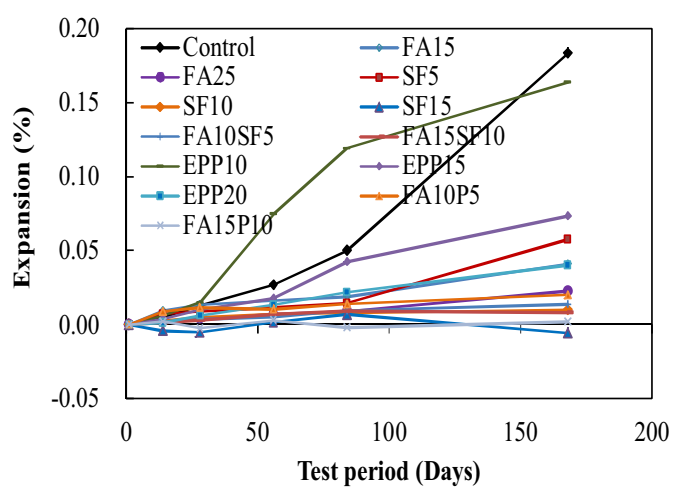

Figure 2. Expansion of mortar with FA, SF, different EPP and mineral combination. 


\subsection{Concrete prism}

Figure 3 showed that without mineral, concrete expansion increased fastly, then enlarge until the end of observation period. It can be seen that there was expansion reduction due to usage of FA. The expansion of concrete with FA15\% was lower than control concrete. Then, the expansion of concrete with FA25\% was lower than concrete with FA at level 15\%. Expansion reduction by using FA 25\% was under $0.05 \%$, that classified as non-reactive.

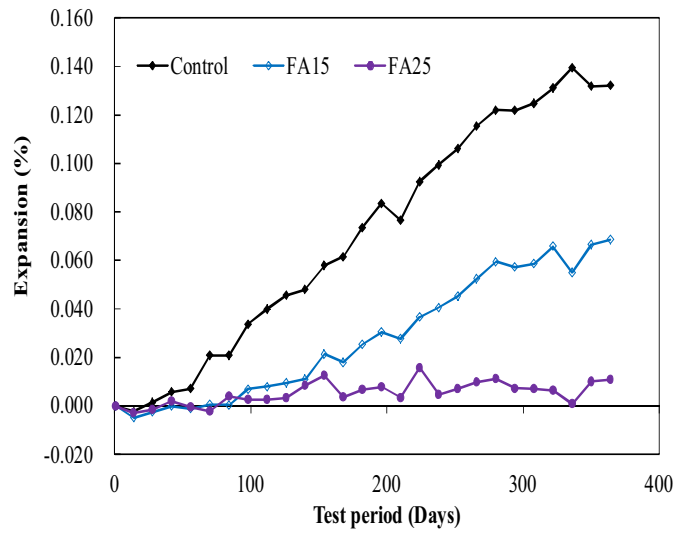

Figure 3. Expansion of concrete with FA.

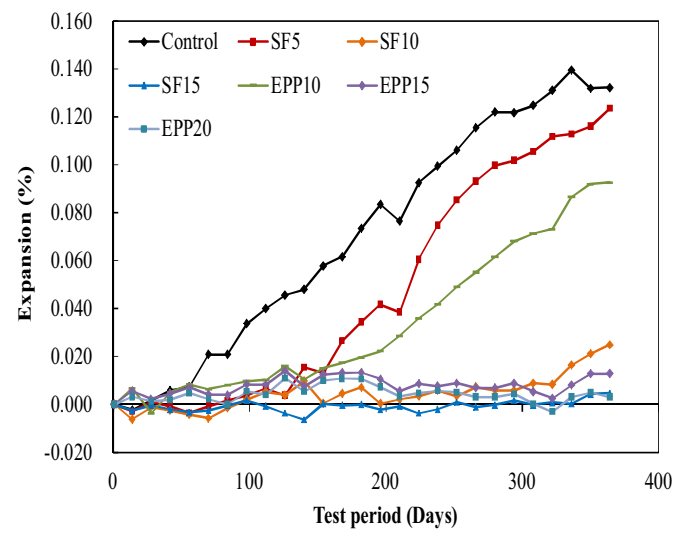

Figure 4. Expansion of concrete with SF and EPP.

Furthermore, concrete expansion with SF, and EPP were shown in Figure 4. Expansion was reduced due to usage of SF and EPP. Control concrete or concrete without mineral, its expansion was large and rapid until the end of the period. The larger the portion of mineral, the lower the expansion will be. As a results, the lowest expansion were achieved at concrete with SF at level 15\%, and concrete with EPP at level 20\%. Furthermore, expansion reduction by using $10 \%$ and $15 \%$ of SF were under $0.05 \%$, that classified as non-reactive. Then, expansion of concrete with EPP at level $15 \%$ and $20 \%$ were under $0.05 \%$, that classified as non-reactive. The expansion comparison of concrete by using FA, SF, EPP, FA in combination with SF and EPP can be seen in Figure 5 and Figure 6. Concrete expansion with combination FA with SF (FA10SF5) and EPP (FA10EPP5) were lower than concrete with FA 15\%. Then, concrete expansion of FA in combination with SF (FA15SF10) and EPP (FA15EPP10) were also lower than concrete with FA 25\%.

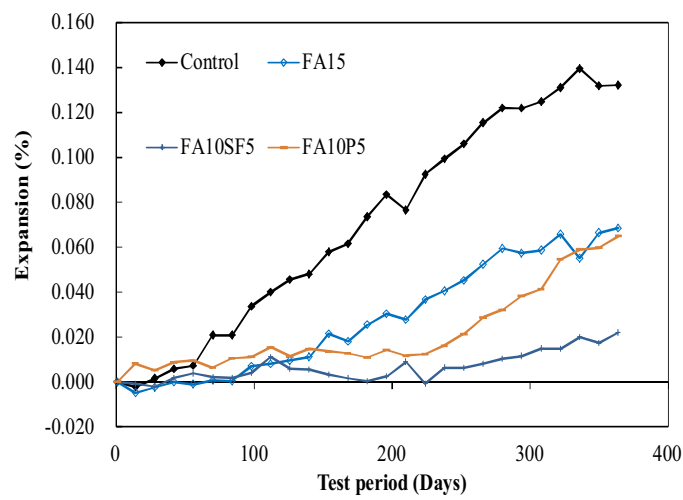

Figure 5. Expansion of concrete with FA15, FA15SF10, FA10P5.

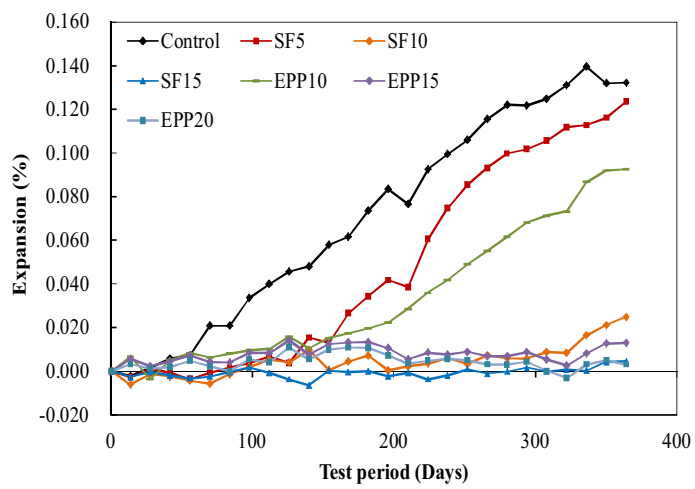

Figure 6. Expansion of concrete with FA25, FA10SF5, FA15P15. 
The combination effect of FA with SF and EPP in order to reduce expansion due to ASR were stronger than FA itself. Furthermore, the comparison of expansion suppression by using all minerals used in this study is shown in Figure 7.

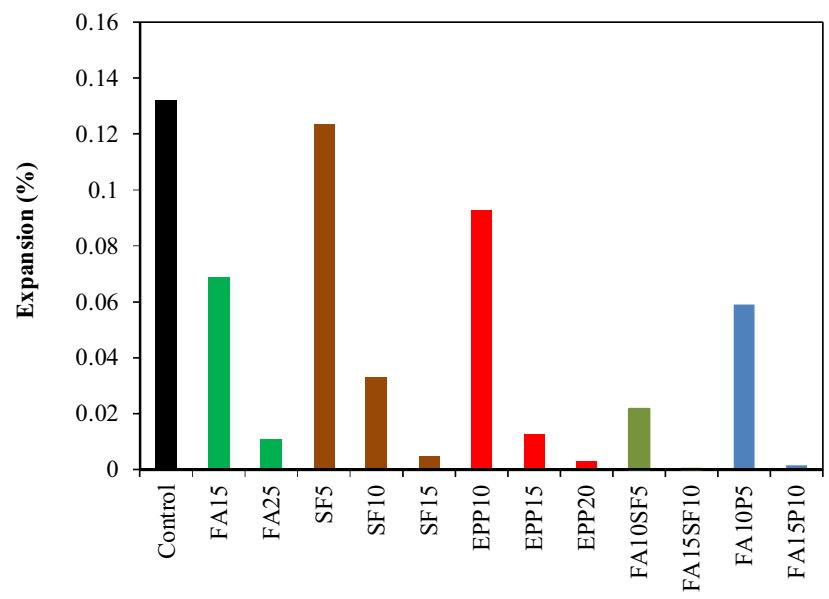

Figure 7. Expansion of concrete with FA, SF, EPP, FA in combination with SF and EPP.

\subsection{Compressive strength of concrete}

The results of compressive strength test at 28 days are shown in Table 3 . It can be observed that the usage of minerals and mineral combination could influence the strength values.

\section{Discussion on the Effectiveness of FA, SF and EPP}

Finer pozzolans are sufficient in mitigating ASR [3]. SF with a particle size of approximately $0.1 \mu \mathrm{m}$ is also very effective in preventing ASR. SF is a reactive pozzolanic material because of its fineness and high amorphous silicon dioxide content. SF reacts with calcium hydroxide $\left(\mathrm{Ca}(\mathrm{OH})_{2}\right)$ to form additional Calcium Silica Hydrate (C-S-H), which is similar to the calcium hydrate formed from the Portland cement. The product of the pozzolanic reaction (secondary C-S-H) can incorporate alkali metal ions into their structure and reduce the alkalinity of the pore solution. At the same time, the secondary C-S-H hydrates fill the adjacent pores and reduce the permeability of concrete, consequently, reducing the free movement of alkali ions[4]. Meanwhile, FA reduces expansion by lowering the alkali concentration and hydroxide ion in the pore solution [5]. Tanaka et al. concluded: the effect of neutralization reaction that the part of alkali ion was consumed in hydrated material while part of FA and SF would react with hydroxide ion. Furthermore, the reduction in alkali concentration of pore fluid was the principal of minerals suppression mechanism [1]. The presence of both FA and SF resulted in low pore solution alkalinity at early and late ages. SF is effective in reducing alkalinity at an early age, meanwhile FA become effective at later ages [2]. The effectiveness of EPP in mitigating ASR can be attributed to pozzolanic activity [6, 7], possessed by the material. In suppressing expansion, the porous nature of EPP might play an important role by providing a distributed air bubble system that accommodates expansive gel in concrete[7]. Furthermore, G.E. Cristidis et al. reported that capable of sodium absorption or posseses binding alkalis property were as a basis for pozzolanic activity of Perlite. FA reduced compressive strength. The compressive strength reduction was related to the properties of FA that declined the heat of hydration. As a result, FA slowed the rate of hardening and reduced the strength [9]. On the other hand, the usage of SF and combination of FA and SF enhanced the strength. The highest strength was achieved on concrete with SF15\%. Meanwhile, the combination of FA and EPP were not significant to increase the strength. 
Furthermore, the compressive strength of concrete with EPP $20 \%$ was larger than control concrete. Demirbogga et al. attributed that the strength improvement of expanded perlite, related to both the selfcuring property and pozzolanic of perlite [10].

\section{Summary}

The results obtained are summarized as follows:

i) Combination of FA with SF and EPP could reduced expansion lower than FA itself.

ii) Combination of FA with SF (FA15SF10) showed the best concrete mixtures in reducing expansion.

iii) The expansion reduction of concrete with FA10SF5, FA15SF10, and FA15P10 were under $0.05 \%$ that classified as non-reactive.

iv) Compressive strength of concrete by using FA in combination with SF showed better than compressive strength of concrete by using combination of FA with EPP.

\section{References}

[1] Yasushi Tanaka, Yuji Hayamizu, and Takuya Sudoh, Combination effect of additives on preventives effect of alkali silica reaction, Cement Science and Concrete Technology (in Japanese), 64, 406-412, (2010).

[2] M.H. Shehata and M.D.A. Thomas, Use of ternary blends containing silica fume and fly ash to suppress expansion due to alkali-silica reaction in concrete, Cement and Concrete Research, 32, 341-349, (2002).

[3] L.R.L Malvar, efficiency of fly ash in mitigating alkali-silica reaction based on chemical composition, ACI Materials Journal, September-October, 319-326, (2006).

[4] G.J.Z. Xu, D.F. Watt and P.P. Hudec, Effectiveness of mineral admixtures in reducing ASRexpansion, Cement and Concrete Research, 25, 1225-1236, (1995).

[5] H. Takahashi and K. Yamada, Critical characters of fly ash suppressing ASR, Proceedings of the $14^{\text {th }}$ International Conference on Alkali-Aggregate Reaction, Austin, (2012)

[6] T.K. Erdem, Ç. Meral, M. Tokyay and T.Y. Erdoğan, Use of perlite as a pozzolanic addition in producing blended cements, Cement and Concrete Composites, 29, 13-21, (2007).

[7] F. Bektas, L. Turanli and P.J.M. Monteiro, Use of perlite powder to suppress the alkali-silica reaction, Cement and Concrete Research, 35, 2014-2017, (2005).

[8] G.E. Christidis, I. Paspaliaris and A. Kontopoulus, Zeolitisation of perlite fines, mineralogical characteristics of the end products and mobilization of chemical elements, Appl. Clay Sci., 15, 305-324, (1999).

[9] R. Demirboğa, İ. Türkmen and M.B. Karakoç, Relationship between ultrasonic velocity and compressive strength for high-volume mineral-admixture concrete, Cement and Concrete Research, 34, 2329-2336, (2004).

[10]R. Demirbŏga, I. Örüng and R. Gül, Effects of expanded perlite powder and mineral admixtures on the compressive strength of low-density concretes, Cem. Concr. Res., 31, 1627-1632, (2001). 